\title{
3
}

\section{ASSESSING THE DEVELOPMENT, IMPLEMENTATION, AND MANAGEMENT OF YOUR COMPREHENSIVE SCHOOL COUNSELING PROGRAM}

\section{Introduction}

In this chapter, we focus on the steps you can take to assess the development, implementation, and management of your comprehensive school counseling program (CSCP). Our goal is to highlight how assessment should be integrated into the creation and annual revision of your CSCP. Often, when you are building a school counseling program for the first time, regardless of the amount of experience you have as a school counselor, the process can feel overwhelming. We also discuss the history and the various approaches to conceptualize CSCPs that are found within the literature.

The current version of the American School Counselor Association (ASCA) National Model argues that school counselors should be action orientated and should utilize various assessments. Implementing several types of new assessments supports the existing data already found within your school. Further, ASCA (2019a) highlights that school counselors should use the National Model as a framework to connect the needs of the school with their already established CSCP. In doing so, school counselors create more data-responsive CSCPs. The revision to the fourth edition of the National Model was intended to streamline the process of becoming a data-driven and data-informed school counselor (ASCA, 2019a).

In addition to streamlining the National Model, ASCA released a revised companion guide, ASCA National Model Implementation Guide: Manage and Assess, which provides school counselors with ASCA-aligned information for the creation of a CSCP within their school (ASCA, 2019b). School counselors can utilize the guide to help build a data-driven CSCP by using the provided guidelines about pre- and postassessments that are aligned with the Mindsets and Behaviors standards of the ASCA National Model. The guide is also intended to help support school counselors throughout the application process of becoming a Recognized ASCA Model Program (RAMP; ASCA, 2019b). Our organization encourages professional school counselors who are interested in becoming a RAMP school to complete the assessment found within the ASCA National Model to gauge the current state 
of their CSCP (2019b). We recognize that each school counselor is uniquely positioned within different school environments. Some schools may not have the possibility of obtaining RAMP status; however, our goal is to equip school counselors with various assessments to assess the status of their CSCP.

Our goal throughout this chapter, and this book, is to emphasize various valid and reliable assessments to support you. In addition, we highlight various approaches to CSCPs. The process of connecting assessment and data collection when working towardsbuilding or revising a CSCP is rarely discussed within our profession. Our intention is to provide you with a wealth of information related to valid and reliable assessments that could fit within your CSCP. Additionally, many states have moved to specific school counseling frameworks and evaluation systems. These are typically aligned with the ASCA National Model and require school counselors to provide supporting evidence of how they are meeting students' needs. School counselors can supply adequate evidence to meet job requirements and serve all students through data collection and assessment. As previously discussed, school counselors often resort to creating assessments due to budgetary restrictions and lack of access to scholarly journals where a multitude of free, valid, and reliable assessments can be found.

Throughout this chapter, we explore various types of assessments that help school counselors define, manage, deliver, and assess their CSCP based on the four quadrants of the ASCA National Model. These four quadrants are: Define, Manage, Deliver, and Assess. We aim to demonstrate that school counselors can use assessments to create data-driven CSCPs that benefit all students. We elaborate on how to use these assessments within your practice by providing ample examples. This chapter demonstrates how assessments contribute to the development, implementation, and management of a CSCP, whereas Chapter 4 showcases assessments to consider in your direct counseling services.

\section{Approaches to Comprehensive School Counseling Programs}

The use of a CSCP or a data-collection process is important because it can close the opportunity and achievement gaps for students. Erford (2019) explained, "achievement gaps are the differences in academic performance among groups of K-12 students based on ethnicity/race, gender, social class, disability status, language status, and other variables" (pp. 176-177). Opportunity gaps refer to the lack of access and quality of resources available to the student that help prepare students for life after graduation (Erford, 2019). Being intentional with your data collection and how you ap-

Being intentional with your data collection and how you approach your CSCP based on the data can help you combat other gaps such as attainment.

Without utilizing assessments or data collection (e.g., attendance, discipline), school counselors would be unaware of the existing opportunity gaps within their school community. proach your CSCP based on the data can help you combat other gaps such as attainment. Attainment gaps refer to the gaps associated with college completion based on a students' minority identity (2019). Without utilizing assessments or data collection (e.g., attendance, discipline), school counselors would be unaware of the existing opportunity gaps within their school community. As discussed in Chapter 1, being an active member of the Multi-Tiered Systems of Support (MTSS) team, the Positive Behavioral Interventions and Supports (PBIS) process, using universal screeners, and collecting data can help close this gap. Additionally, there are different approaches of CSCPs that school counselors can implement when developing their own methods of collecting data.

As Dahir and Stone (2006) noted, the ASCA National Model was born out of the work of many scholars and influences the changing landscape of our education system. For the purposes of this 
chapter, we focus on the work of Johnson and Johnson (2002) and Gysbers and Henderson (2001). While we focus on the aforementioned authors' work, it is important to note that Dr. Robert Myrick has published several editions of his original book on this subject matter, initially published in 1978 titled Developmental Guidance and Counseling: A Practical Approach. He is noted within the professional literature for his contributions and we have included his most current edition within our reference list (Myrick, 2011).

A common thread among these approaches is a focus on school counseling curriculum (Nelson \& Tarabochia, 2020). Our interpretation for this commonality, is school counseling curriculum is widely accepted within the profession as a foundational direct service provided to all students. DuFour et al. (2002) proposed a collaborative approach for learning organization for collaborative data collection and assessment of school programs aligned with the ASCA domains of academic, career, and social-emotional (formerly personal-social) development (Johnson \& Johnson, 2002). From our perspective, DuFour et al. were describing modern-day CSCPs working in tandem with PBIS and MTSS frameworks. Ironically, they project into the year 2021, stating that school counselors will utilize technology to service students in new ways, collect and track large amounts of data, and highlight the impact technology will have on collaborative relationships (DuFour et al., 2002). Furthermore, Gysbers and Henderson (2001) stressed the importance of having a clear operational system that allows school counselors to work from and provide services for students. Whether you are utilizing a state-created approach or a different approach to your CSCP, it is important to ensure you are working to collect data that informs the programs and services provided to students. For example, several states have created guides for CSCPs. The Missouri Comprehensive Guidance and Counseling Program provides school counselors with a process for creating, updating, and growing a CSCP (Gysbers et al., 2017). Additionally, the state of Ohio has made a comprehensive school counseling manual available to Ohio-based school counselors that is linked to the Ohio school counselor evaluation process (Ohio Department of Education [ODE], 2016a, 2016b).

It is important for us to discuss how we began the practice of CSCPs by exploring the history of the ASCA National Model. With collective changes in the educational system, changes to our profession have been warranted. Dahir and Stone (2006) discussed educational reform in connection to the professional responsibility of school counselors to ensure all students' needs are met. In order to do this, we needed to have a system that allows us to collect, assess, and manage data. Not only do we need a system that supports us in organizing our data, but we need a system that allows us to house our programming and monitor how students change after engaging in our program.

Since the inception of the ASCA National Model in 2003, several approaches to CSCPs and data collection have emerged, and some include a social justice focus. ASCA (2012) started the development of the first National Model by gathering a group of school counseling experts together for 2 years before releasing the first National Model. Bringing together individuals with school counseling knowledge and experience was done in response to the need for school counselors to incorporate data into their school counseling practice to demonstrate their ability and the value they bring to their schools (ASCA, 2012). Drs. Trish Hatch and Judy Bowers developed the first National Model and supported ASCA in the revisions to the third edition (2012). Next, we explore an approach connected to CSCPs that uses a social justice lens.

Dahir and Stone (2009) studied school counseling programs with a connection to social justice. This study reminded us of the Change-Agent-for-Equity (CAFE) Model, which connects social justice to CSCPs. Mason et al. (2013) developed the CAFE Model to build upon the ASCA National Model to provide school counselors with an additional framework rooted in social justice. The CAFE Model 
expands on what it means to be a change agent to provide school counselors with an action-oriented approach to delivering programs and services. School counselors are committed to CSCPs that are rooted in providing services at all levels that are inclusive while embracing their professional identity. Within this section, we continue to expand on the work of those who have influenced the creation and evolution of CSCPs while describing more recent approaches available to school counselors.

The Use of Data in School Counseling (Hatch, 2014) connects the CAFE Model to our work and our commitment to grow as social justice advocates who use data to close the opportunity gap for students. Hatch (2014) outlined data collection for school counselors in a way that bridged the gap between ideal school counseling data-collection methods and the reality of the day-to-day school counseling career. In Hatch's book, the approach to school counseling programming is rooted in manageable steps and interconnecting data. For example, Hatch highlights the importance of data and data dissemination through systems in your school, such as Multi-Tiered, Multi-Domain Systems of Support (MTMDSS), MTSS, and PBIS teams. It is important for school counselors to understand the multiple systems at play within a school system and how many of these systems are directly connected to our work as school counselors. To highlight this point, Goodman-Scott and Ockerman (2019), clearly highlight the working relationship between MTSS and CSCP as well as the empirically based research that has been conducted on the alignment of CSCP, MTSS, and PBIS. We have referenced Goodman-Scott et al's (2019) edited book, The School Counselor's Guide to Multi-Tiered Systems of Support, in Chapter 1 as well as this chapter as we feel it provides our readers with additional information on the connection of MTSS within the practice of school counseling. Goodman-Scott and Ockerman (2019) suggested incorporating MTSS team members into the Advisory Council as a way to connect the two systems with intentionality. Additionally, they recommend that school counselors include foundational MTSS components within the annual agreement, mission, vision, and other core tenants of the CSCP. Connecting these systems helps to clearly depict the integral role the school counselor and the CSCP can have within a school.

As discussed in Chapter 1, Hatch takes similar approaches within her work. Specifically, in The Use of Data in School Counseling, Hatch (2014) introduces,

Data allow us to be better advocates, leaders, and agents of change.

"While guidance is often provided for every student,

the concept behind intentional guidance is some kids need more" (p. 37). We want to recognize that as a profession we are moving away from the word guidance to discuss any of our work as professionals. However, it is extremely important to highlight the meaning behind the quote cited here. To us, Hatch (2014) was stressing the importance of using data, the ASCA National Model, MTSS, and PBIS in connection with evidence-based practices to be intentional in everything we do as school counselors. This is why operating within a data-driven CSCP is critical. Why? Because data give voice and evidence to our gut feelings as school counselors. Data allow us to be better advocates, leaders, and agents of change.

Zyromski and Mariani (2016) wrote Facilitating Evidence-Based, Data-Driven School Counseling: A Manual for Practice which can work in tandem with the ASCA National Model. The authors highlighted that data collection and evidence-based school counseling programming can be a process rather than a model for school counseling. Through their book, they discuss the purpose of setting goals and using data-driven decision-making to help school counselors prioritize their time. Zyromski and Mariani expand on the Logic Model, which they adapted from Dimmitt et al.s (2007) book, Evidence-Based School 
Counseling: Making a Difference with Data-Driven Practices. The Evidence-Based School Counseling Logic Model includes the following seven items: assess, data indicators, data goals, interventions, logistics, evaluation, and evolution. These elements are integrated throughout their book as they walk readers through how to incorporate the Logic Model within the practice of school counseling by first starting with the data indicators. They explain that school counselors can use the model to pinpoint important data and "drill down" into the data to dissect and describe how students are being impacted (Zyromski \& Mariani, 2016). This can be done to narrow in on the gaps for populations of students and allow the school counselor to locate the most appropriate interventions, ideally evidence based, to support student growth within a CSCP. Also, the school counselor can use the model to highlight logistics of their programming, the evaluation, and the evolution of the services (2016).

Similar to Hatch's approach, Zyromski and Mariani walk school counselors through the process of connecting data to their CSCP while highlighting Dr. Hatch's Flashlight approach to disseminating information. The Flashlight approach was adapted from Weiss's Logic Model as a way to visually describe the results of your CSCP in relation to data as a way to demonstrate to key stakeholders the results of your program (Hatch, 2014). Utilizing this approach is typically done through a structured digital presentation, for example, PowerPoint, while encompassing the ASCA National Model. For example, Zyromski and Mariani, highlighted that the Flashlight presentation should include ASCA Mindsets and Behaviors that were addressed withing the selected lessons or programs utilized within your CSCP. They continue to expand on Hatch's original idea to encourage school counselors to use school data coupled with intentional graphics (Zyromski \& Mariani, 2016). Hatch (2014) includes a Flashlight Rating Scale Rubric to help school counselors evaluate their presentation. We encourage our readers to review the examples and in-depth details of this approach in Hatch's (2014) book as well as Zyromski and Marinai's (2016) book.

Just as our colleagues, Zyromski and Mariani (2016) mentioned in their book, the ideas around data collection and CSCP are not our own, but rather a collection of all the great work that has been disseminated related to how to organize and communicate your CSCP. We hope to add to these concepts by offering the importance of assessment in the development and implementation of your CSCP and as a way to continue to enhance our profession. We encourage our readers to explore the approaches discussed within this section to see how they can fit within your practice. Next, we explore the importance of engaging in self-assessment as a school counselor. As we have mentioned throughout Chapters 1 and 3 , our goals are to provide you with ways to integrate assessments into your CSCP to help you continue to build upon the approaches to CSCPs.

\section{Self-Assessment}

It is important to engage in self-assessment regarding your attitudes, skills, and knowledge related to your school counseling program in order to understand their influences on your CSCP. This allows you to best meet the current needs of students and establish, or further enhance, your school counseling program. It can be overwhelming to build or restructure school counseling services. Thus, we recommend the practice of self-assessment as it provides you with direction and action steps to support the process.

Conducting self-assessments aligned with our professional standards, both the ASCA standards and applicable state standards, is a great place to start. Upon our review, we found a comprehensive assessment within the National Model is the ASCA School Counselor Professional Standards \& Competencies Assessment (ASCA, 2019a). School counselors can use this assessment to measure the effectiveness of their CSCP on the Mindsets and Behaviors standard of the National Model. 
The assessment can also be used to create an action plan for implementing or revising a CSCP (ASCA, 2019a). Another self-assessment aligned to the ASCA National Model is the School Counseling Program Implementation Survey (SCPIS). The goal of the SCPIS is to help school counselors understand how their CSCP is being implemented to align with the ASCA National Model (Clemens et al., 2010). The assessment is based on the existence of essential components of CSCPs, which include, but are not limited to, a mission statement, goals and objectives, and data. Another related self-assessment is the School Counselor Activity Rating Scale (SCARS), which was designed to measure any discrepancies between a school counselor's goals for their work activities and their actual work activities (Scarborough, 2005a). In Chapter 4, we discuss additional assessments and how to incorporate each into a school counselor's work practice.

\section{Assessment Related to the ASCA National Model}

The process of creating a CSCP that is informed by assessment data helps to support school counselors' efforts in creating CSCPs that meet the needs of all students. School counselors learn the needs of their students and key stakeholders through the use of assessments. What follows is a discussion of how assessments directly connect to the Define, Manage, Deliver, and Assess quadrants of the ASCA National Model. In addition to briefly describing the goal of each quadrant, we connect each quadrant to specific assessments that align with the purpose of each respective quadrant.

\section{Define}

The Define quadrant of the ASCA National Model opens by explaining the importance of using the foundational documents to inform our practice as school counselors (ASCA, 2019a). For example, both the ASCA Mindsets \& Behaviors for Student Success: K-12 College-and Career-Readiness for Every Student and the ASCA School Counselor Professional Standards and Competencies are explicitly explained within this section to highlight the intentionality of their design that connects to the other quadrants within the National Model (2019a). Our focus within this book is to continue to connect the importance of data and assessment to the meaningful work you do as a school counselor. We can see this shift throughout our profession and within ASCA. Indeed, ASCA (2019a) explains that the ASCA Mindsets and Behaviors standards were conceptualized and informed by college and career documents created by various organizations. This exemplifies how our profession continues to shift toward being more data driven and research informed. Additionally, ASCA summarizes the use of a noncognitive factors framework for the ASCA Mindsets and Behaviors standards and provides key literature supporting the rationale related to the organizational design and the final product.

The overarching goal of the Define quadrant is to show the significance of these ASCA documents and how they intersect with the formation of a CSCP. The second goal is to provide implementation steps for school counselors. The key documents include student standards of the ASCA Mindsets \& Behaviors for Student Success: K-12 College-and Career-Readiness Standards for Every Student (2014), the ASCA Ethical Standards for School Counselors (2016), and the ASCA School Counselor Professional Standards and Competencies (2019c). In addition, the goal of the Define quadrant is to provide these key documents in one place for school counselors to utilize as they work through the National Model. Our professional organization makes these documents readily available in portable document format (PDF) on its website for free and in books available for purchase published by ASCA. We have intentionally cited these stand-alone key documents throughout this book to support accessibility for our readers. Now, let's explore the use of the SCPIS. 


\section{School Counseling Program Implementation Survey}

Elsner and Carey (2005) initially developed the SCPIS as an unpublished instrument that was cited by Clemens et al. (2010). As originally developed, the goal of the survey was to use clear language that was both observable and measurable (Clemens et al., 2010). The survey began with 25 questions. After conducting an internal consistency reliability analysis of the questions, the SCPIS was reduced to 20 questions (2010). The researchers took the remaining questions and conducted two separate studies. During the first study, the survey was sent to several states to better understand and evaluate the possible outcomes related to the professional relationship between school counselors and school administrators (Clemens et al., 2009). Clemens and colleagues worked with the Center for School Counseling Outcome Research, located at the University of Massachusetts Amherst, to conduct a statewide study. The SCPIS aims to assess the current level of a school counseling program's utilization of the ASCA National Model through the school counselor's self-examination of what they currently have in place in their CSCP (2010). Each question on the SCPIS asks participants to respond on a 4-point scale, ranging from "not present" to "fully implemented." Our readers can find a copy of the SCPIS within the Clemens et al. (2010) article. We recognize that many of our readers have limited access to journal articles, however, ASCA members have access to this article with their ASCA membership.

It is important to note that there have been updates to the ASCA National Model since Elsner and Carey (2005) originally developed the scale and since Clemens et al. (2010) conducted an exploratory factor analysis (EFA). Nevertheless, the survey items still align with the foundational structure of the National Model. Despite the updated National Model, we feel the SCPIS can be a valuable tool for school counselors. Let us examine the first checklist item of the survey, "a written mission statement exists and is used as a foundation by all counselors" (Clemens et al., 2010, p. 134). The rationale for having this be the first question is to ensure that all school counselors have adopted their own personal or a collective mission statement developed by a team of school counselors and are using this statement as a working definition for their CSCP. The Define quadrant provides a foundation of important documents related to the professional identity of a school counselor in order to help the school counselor develop a well-informed and intentional mission statement. In the Manage section, we cover assessments that continue to help school counselors build and assess their CSCP. The SCPIS is an effective tool to use to determine where your school counseling program is before moving to the Manage section of the ASCA National Model.

The additional questions in the SCPIS assessment cover relevant and current school counseling practices. The second question within the SCPIS addresses the overall delivery of school counseling services to ensure all students are served through a CSCP. The third question continues to build upon the foundations by addressing fairness and equity by assessing whether the school counselor has action plans associated with the achievement gap or what is also referred to as the opportunity gap within educational literature. The SCPIS includes a question on utilizing needs assessment regularly, but does not address whether the needs assessments, and others like it, are reliable and valid. As we previously indicated, self-created assessments are considered informal assessments, which we address in Chapter 5.

After completing all 20 questions, our recommendation is to highlight or color-code your answers to indicate items that are absent from your program as well as items that are completely present. We suggest making a column that includes all items in your CSCP that are data informed and then creating a running list of elements that require your attention. Focusing on the aspects missing from your CSCP, let us say that it is five out of the 20 presented questions, we recommend starting with two or three items to avoid getting overwhelmed. For example, if your CSCP is missing a mission statement along with goals and objectives, it is important to first develop these items as they are the foundation of your program. 
As emphasized by ASCA (2019a), the mission statement helps to focus the school counseling program, provide it with direction that aligns with the vision, and helps to shape the goals and objectives. It is recommended to use the specific, measurable, attainable, results-oriented and time-bond (SMART) goal format to form goals and objectives, as described in Chapter 2. When initially developing your CSCP, we recommend starting with the SCPIS within the Define section to help ease any feelings of being overwhelmed. We continue to build upon understanding the Manage section as well as connecting other assessments that align with it.

\section{Manage}

The Manage quadrant provides school counselors with a system to keep their CSCP organized (ASCA, 2019a). The idea is to provide a structured system that allows school counselors to manage the multiple hats they wear within their professional role and to carry out effective school counseling programs. School counselors can use this framework to find tools and assessments to manage their CSCP. Indeed, as ASCA (2019a) highlighted, "The assessments and tools help school counselors develop, implement and assess their school counseling program based on clearly defined priorities reflecting student needs" (p. 29). Establishing these priorities in connection with student needs demonstrates the efforts school counselors take to map out the various types of data, from multiple data sources, that they need and use within their CSCP to support the exact needs of their students. Documenting the CSCP with the ASCA-provided templates is a large focus of the Manage quadrant. Throughout the Manage quadrant, ASCA clarifies how to connect each template with data, which creates a building-block structure between each template.

The goal of the Manage quadrant is to combine the standards and initial data from the Define quadrant to develop and monitor programming within a CSCP by using action-oriented templates (ASCA, 2019a.) The Manage quadrant intentionally builds upon the Define quadrant to help school counselors clarify the focus of their CSCP. This is achieved by creating a vision and mission statement that is later connected to assessment data. The goal of a strong connection to data is to drive home the importance of how powerful data are in informing CSCPs.

\section{Needs Assessments}

As discussed in Chapter 2, needs assessments are often informal assessments created by school counselors to gain feedback regarding the unique needs of their school. While our focus is to highlight the importance of using valid and reliable assessments, we recognize that school counselors will need to use informal assessments, such as needs assessments, to gather input from key stakeholders. Throughout this section, we discuss some self-assessments that school counselors can use to support their school counseling program to gain additional information from stakeholders.

In the Manage section, ASCA (2019a) highlights that, "supplemental methods solicit additional information from students and relevant stakeholders about the need identified in school data" (p. 37). This is where a needs assessment can support school counselors in selecting, building, and creating materials for their CSCP. To do so, ASCA (2019a) recommends the following pathways for gathering additional information, "methods include conversation, interviews, needs assessments, climate survey, and opinion surveys" (p. 37). Using other pathways to gather data can provide you with additional information and context that can be applied to your school counseling program.

As noted in the ASCA National Model, and similar to what we have mentioned throughout this book, it is important not to rely on one form of data, but rather use formal and informal assessments together. The following sections highlight other assessments that can support your CSCP program and 
provide examples of how to incorporate these into practice. These self-assessments are focused on your role as a school counselor and understanding your job functions.

\section{School Counselor Activity Rating Scale}

The School Counselor Activity Rating Scale (SCARS) is a self-assessment tool that is designed to measure how professional school counselors spend their time in comparison to how they would actually prefer to spend their work-related time. If school counselors are interested in a copy of the SCARS, Scarborough (2005a) highlighted in her 2005 article titled The School Counselor Activity Rating Scale: An Instrument for Gathering Process Data, that school counselors can access a copy of the SCARS by directly emailing her. Additionally, a copy of the SCARS can be located though the UMass Amherst School Counselor Resources web page (UMass Amherst College of Education, 2019); the link is located within the tools and resources section of this chapter. This self-assessment can help support school counselors in collecting self-reflective data. The SCARS assessment and its components (i.e., actual and prefer scale) connect to the ASCA National Model Manage section pertaining to constructing a school counseling program that is connected to role-appropriate duties. Some of the questions found within the SCARS are considered to acknowledge role-inappropriate duties. For example, if a school counselor prefers the job functions of a test coordinator, then this would be a point of evaluation for the school counselor or school counseling team as the job function could be taking away from providing direct services to students.

Scarborough (2005b) outlines her stages of development of the SCARS as two phases; the first phase focused on the creation of the assessment including layout, question format, and scaling structure. Then, in phase two, the product of phase one was pretested (Scarborough, 2005a). To develop the statements that are found within the SCARS, Scarborough (2005) used the ASCA's working definitions of how services are delivered; this includes what we now refer to as direct (individual, small group, and classroom lessons) and indirect services (other services, such as consultation and collaboration, that are focused on supporting students and the school counseling program). The SCARS includes what Scarborough referred to as clerical duties, which are now commonly referred to as role-inappropriate duties in the ASCA National Model.

Though dated, the SCARS can still be used in a variety of ways. School counselors can use this to advocate for role-appropriate duties with administrators. Additionally, a school counseling team could use the SCARS as a way to determine each team member's preferences. Then the team could collaborate together to establish preferred tasks within a CSCP. In the next section, we focus on a tool that helps school counselors better understand their time. This connects more to the data-collection focus of this book and how assessments also connect to one another.

\section{School Counselor Use of Time Analysis}

While the School Counselor Use of Time Analysis (SCUTA) is not an assessment, but rather a tool, it is important to highlight its functions as it supports the development of a CSCP that is connected to the ASCA National Model. This interactive computer-based tool helps school counselors keep track of their time and document information to build a data-informed CSCP (SCUTA, 2020). While there is a free trial available, SCUTA has costs associated with purchasing a license, depending on the version: Lite, Pro, Max, R, SD, or University. One of the main functions of the SCUTA is that it allows school counselor to run analyses of how they are using their time. In addition, school counselors can keep detailed notes on their daily, weekly, and monthly activities through a secure login. This process can be especially helpful for school counselors during annual evaluations with administrators. We discuss this tool and its utility in greater detail in Chapter 6. 


\section{Deliver}

The Deliver quadrant of the ASCA National Model explains how school counselors' time should be spent. Two major categories-direct student services and indirect student services-divide a school counselor's time (ASCA, 2019a). Under the direct student services umbrella, ASCA uses the categories of instruction, appraisal, advisement, and counseling to dissect how school counselors directly serve students. Therefore, ASCA (2019a) clearly connects to the ASCA Mindsets \& Behaviors for Student Success: K-12 College and Career Readiness Standards for Every Student by emphasizing the importance of intentionality of services. The indirect student services a school counselor provides are achieved through an advocacy lens to help support the educational experience of each student. ASCA (2019a) defines indirect student services as the school counselor's work that involves consultation, collaboration, and referrals on behalf of the student. The two overarching categories of student services (i.e., direct and indirect) are divided by the 80/20 rule, respectively. As we have discussed in Chapters 1 and 2, the 80/20 rule means that $80 \%$ of a school counselor's time should be spent working directly with students (e.g., classroom lessons, small groups, one-on-one). The remaining $20 \%$ of a school counselor's time should be spent advocating for students through indirect service as a collaborator, consultant, and by completing referrals for additional services for students that are beyond the scope of the school counselor (ASCA, 2019a). For example, a school counselor can be a collaborator and consultant through membership on the MTSS or PBIS team. As a member of these teams, the school counselor can collaborate with other team members to make decisions on school-wide programming and provide consultation or support services for individual students.

The goal of the Deliver quadrant is to explain the school counselor's role for direct work with students and the indirect services that are provided on behalf of the students. To reiterate, ASCA clearly explains what ratio of time should be spent on each type of service. To make a clear connection as to how assessments can be connected within this quadrant, we are going to first expand on the direct student services categories of instruction, appraisal, advisement, and counseling. ASCA (2019a) states that, "instruction includes teaching the school counseling curriculum to students focused through the lens of selected student standards from the ASCA Mindsets \& Behaviors" (p. 78). This includes school counselors working with students in whole or small groups to deliver content to support student development related to academic, career, and social and emotional learning. These lessons are intentional and are connected to the school counselor's CSCP.

The Deliver quadrant continues to expand on other services, including appraisal and advisement. Indeed, ASCA defines this as two-steps to support students in their development and is connected back to the ASCA Mindsets \& Behaviors through direct services (ASCA, 2019a). According to ASCA (2019a), "appraisal is the process where school counselors work with students to analyze and assess their abilities, interests, skills and achievements" (p. 80). The appraisal process occurs by using preexisting data and gathering new data via assessments (2019a). This step of the process is where valid and reliable assessments can help support school counselors through the appraisal process. School counselors can use inventories, surveys, and assessments that provide information about a student's performance. This could be in relation to executive functioning, organization, peer relations, or career planning. However, career is a common topic of conversation with students within the appraisal process-particularly with students in grades 7 th to 12 th. The appraisal process may be more focused on needs associated with being successful within the classroom for younger students. Advising builds on appraisal by taking the information learned and working with students to create an action plan (2019a).

School counselors can support students' social and emotional needs in the form of individual, smallgroup, and core curricular classroom lessons (ASCA, 2019a). While school counselors do not provide 
long-term counseling, they do work with students to help support their development as it relates to the academic, career, and social-emotional domains (2019a). In our role of supporting students within our scope and practice, valid and reliable assessments can provide additional data to enhance our practices. Various assessments can be used to gather information on where a student is, and in turn can be used to advocate for a student's needs with key stakeholders.

\section{Strengths and Difficulties Questionnaire}

Goodman (1997) created the Strengths and Difficulties Questionnaire (SDQ), which comes in multiple versions, including a parent, teacher, and student report. Since the creation of the SDQ, it has become a popular tool to use to gain more insight into children's mental health wellness (Goodman et al., 2010). The parent report is intended to be used to record information on children between the ages of 4 and 16. The teacher report is divided into two reports: one for ages 4 through 11 and another for ages 11 through 16. The student self-report is intended for students between the ages of 11 and 16 . Originally reported by Goodman (1997) and Goodman et al. (1998), the SDQ was intended for ages 4 through 16. However, the website where the SDQ versions are housed, in multiple languages, includes age ranges from 2 to 18 years and older. School counselors can access copies of the SDQ as a downloadable PDF for free. The link can be found within the tools and resources section of this chapter.

As a whole, the various versions of the SDQ are behaviorally based screeners intended to measure both internalizing and externalizing behaviors that lead to an overall Total Difficulties Score (Goodman, 1997; Goodman et al., 2010). In addition to this total score, the screeners are broken into five subscales: Emotional Symptoms, Conduct Problems, Hyperactivity/Inattention, Relationship Problems, and Prosocial Behavior, which include five questions for each of the subscales (Goodman et al., 1998). The SDQ was measured against another similar valid and reliable questionnaire and found that it performed as well as the other questionnaire (Goodman, 1997). Additionally, a pilot study was conducted on the SDQ self-report version to demonstrate promising validity, but concluded more research was needed (Goodman et al., 1998).

While the SDQ has been wildly popular in clinical settings related to better understanding children and adolescent mental health (Goodman et al., 2010), the SDQ can have a wide application to your school counseling practice and can be a valuable tool for collecting data. Through consultation and collaboration, the SDQ can be used to gather more information from the teacher, parent, and the student (if age appropriate) on the child's behavior. This information can be used within your MTSS team to discuss and determine the best services for your student(s). Additionally, through your CSCP, this information can be used as a discussion point with parents during conferences to discuss the referral of community-based counseling services. It is important to remember that our role is to advocate for students using data. As we discussed in Chapter 2, it is important to have multiple forms of data when determining program and services for students. Now we explore how to evaluate your CSCP through application of the Assess quadrant of the ASCA National Model.

\section{Assess}

The Assess quadrant focuses on the results of the school counselor's CSCP. School counselors confirm student learning within CSCPs by analyzing data. Indeed, ASCA (2019a) states, "School counselors engage in assessment to inform potential improvements to school counseling program design and delivery and to show how students are different as a result of the school counseling program" (p. 85). Assessments provide additional data regarding student learning and growth through participation in CSCPs. 
The Assess section highlights how to engage in program assessment by using the School Counseling Program Assessment, which includes standards for CSCP programs that are aligned with the ASCA National Model (ASCA, 2019a). We were unable to find any information on the validity and reliability of this assessment; however, as we pointed out in Chapter 2, informal assessments also provide school counselors with valuable information. Furthermore, ASCA guides school counselors to review their responses after completing the self-assessment to determine the areas of strength, the potential for growth, and their plans to improve their CSCP (2019a). While engaging in your own assessment for professional growth, it is important to assess your program for student growth.

Other components of the Assess section include an explanation of annual results reports as well as how to use these reporting methods to support a CSCP. Again, ASCA (2019a) explains that results reports should be data-informed. To accomplish this, ASCA (2019a) provides school counselors with two types of annual results reports: Classroom and Group Mindsets \& Behaviors Results Report and Closing-the-Gap Action Plan/Results Report. School counselors enhance their programming by collecting data from these reports and by collecting Participation, Mindsets \& Behaviors and Outcome data (ASCA, 2019a). These three types of data are discussed in detail in the forthcoming chapters.

The analysis of the Classroom and Group Mindsets \& Behaviors Results Report is an ASCA-provided template that helps school counselors collect and organize all of the information and data from both wholegroup and small-group lessons (ASCA, 2019a). The assessment template is structured around Participation, Mindsets \& Behaviors, and Outcome data. The template provides school counselors to determine three data-focused questions in the Implications section, which probe the school counselor to determine ways to use the data to inform their ongoing practice (2019a). Additionally, other questions help school counselors analyze their classroom- and small-group services-specific data. The Closing-the-Gap Action Plan/Results Report, which is also highlighted in the Manage section, describes how to analyze the results (2019a).

The ASCA School Counselor Professional Standards \& Competencies Assessment is provided within the Assess quadrant, which is intended as a self-assessment for the school counselor to inform their assessment of their professional practice (ASCA, 2019a). Further, ASCA (2019a) states, "the assessment is a self-report of the acquisition of the mindsets and behaviors school counselors need to meet the school counseling profession's rigorous demands and pre-K-12 students' needs" (p. 94). School counselors can use the ASCA School Counselor Professional Standards \& Competencies Assessment to create a professional development plan (2019a) or use it in conjunction with their state-mandated school counselor's evaluation.

The Assess quadrant provides additional guidance and direction regarding how to share information about the school counseling program. Some ideas include sharing information via the school counselor webpage, through the creation of graphics or digital presentations, as well as other means of communication as highlighted by the ASCA National Model (ASCA, 2019a, p. 93). We have seen school counselors post informative information through their "School Counselor's Corner" webpage that is housed within the school's website. The key takeaway is to refrain from keeping information related to a program's success in a locked file. Rather, the goal is to disseminate this information in the community to show the value that the CSCP and the school counselor as a whole bring to the student body and subsequent student growth (2019a). Additionally, school counselors can use Dr. Hatch's Flashlight approach to disseminating information that was discussed earlier within this chapter. For more ways to highlight and promote your CSCP, refer to Chapter 6.

While one of the goals of the Assess quadrant is to help school counselors organize their data, ultimately, we are gathering this information to show how students were impacted by participation. This organization is achieved by providing school counselors with guiding questions to organize the reporting process of their data. The overarching idea is to ensure that school counselors can effectively communicate their student success program accomplishments to inform key stakeholders. 


\section{School Counselor Evaluation}

It is important for us to address your role as a school counselor, where you are employed, and how you are evaluated by your district. We do so by showcasing a few state evaluations. Some state evaluations require you to provide evidence of how you serve students through your CSCP. For example, several states have adopted their own statewide school counselor evaluation systems. In this section, we highlight a few state examples as well as the ASCA National Model School Counselor Performance Appraisal Template, which administrators use to evaluate school counselors' performance (ASCA, 2019a). The following sections will highlight the various school counselor evaluations.

\section{Ohio School Counselor Evaluation Model}

The Ohio Department of Education (ODE) has a state-specific evaluation process and standards for school counselors. In 2015, the state adopted school counseling standards in response to changes in Ohio law regarding how educators are evaluated to better support school counselors in their professional role (ODE, 2020). As outlined in the Ohio Standards for School Counselors, developing the evaluation included support from the Ohio School Counselor Association (OSCA), which saw the need to create a set of Ohio-based standards to support both school counselors and evaluators through the new Ohio evaluation system (ODE, 2015). What is unique about the development of the Ohio school counselor evaluation process is the external documents that were considered in the creation of the system. The ODE (2015) formed a writing team that reviewed the ASCA National Model, the National Board School Counseling Standards, and training standard issued by Council for Accreditation of Counseling and Related Educational Programs (CACREP) for counselor preparation programs (2015).

The Ohio standards are to be used by school counselors to provide an overview of what is expected of them as a school counselor while providing opportunities to continue to grow (ODE, 2015). Additionally, adopting statewide school counseling standards helps to support professional continuity among districts regarding the professional role of the school counselor (2015). Having a state standard that outlines a CSCP as a role-appropriate function is critical. This allows school counselors to advocate for time and space to evaluate data and develop a CSCP, as it is tied to their state standards. Other standards include a focus of direct services, data, leadership, advocacy, and continued professional development.

The evaluation framework, as highlighted by the ODE (2016a), was designed to incorporate the newly created Ohio School Counseling standards into an evaluation model. This allows administrators the opportunity to evaluate school counselors in relation to their professional role rather than using a standard teacher evaluation. The standards-based model works to support school counselors in their growth while considering all areas of performance and their continued commitment to student outcomes (2016a). The model is composed of four ratings, including ineffective, developing, skilled, and accomplished. Each of these rating areas is later addressed for each of the standards (2016a).

The Ohio School Counselor Evaluation Model manual provides a complete overview of the framework and process for evaluating school counselors (ODE, 2016b). The manual includes guidelines and examples for the observation process for both formal and informal observations. Additionally, it outlines the expectations for both the school counselor and the evaluator during the review process. The Ohio school counseling standards, framework, and evaluation model appear to be most in line with the ASCA National Model and ASCA's School Counselor Mindsets \& Behaviors. The Ohio documents are representative resources for other states wanting to adopt statewide standards or an evaluation process for school counselors.

\section{Colorado Special Services Providers: School Counselors}

The Colorado Department of Education (CDE; 2016) has its own manual regarding school counselors' practice-Colorado State Model Evaluation System for Specialized Service Professionals: Practical Ideas Guide for Evaluating School Counselors. The manual was developed in 2016 after a pilot study was 
conducted. During the 2013 to 2014 school year, the CDE (2015) conducted a pilot study on their state school counselor evaluation system. The CDE has a specific scoring rubric called, Rubric for Evaluating Colorado Special Services Providers: School Counselors, that is used to evaluate school counselors (CDE, n.d.). It is important to note that an updated evaluation model could not be located in connection to the recently updated ASCA National Model.

The CDE manual outlines the passage of Colorado's Senate Bill 10-191, which mandates all licensed individuals working within Colorado schools must be evaluated annually and details the improvements that have been made to the evaluation process for school counselors. To address the unique roles and services provided by school counselors, the CDE completed a pilot study of the school counseling specific evaluation and found that $96 \%$ of all school counselors were at least proficient within their professional role on a 5-point rating scale within 12 school districts (CDE, 2015). The study stated, "school counselors performed the best on Standard 1 (Professional Expertise) and Standard 4 (Reflect on Practice). Standard 3 (High Quality Delivery) was the standard with the most school counselors below the level of proficient" (2015, p. 1). Additionally, a positive shift was reported in all areas of the state model evaluation system in comparison to the former system (2015). The CDE (2016) highlights within the manual that it recognizes that not all school counselors will be working within or from a CSCP. However, school counseling programs should be student centered, data driven, sustainable, evaluated, regularly and focused on student needs, which is in line with the ASCA National Model when this document was published (CDE, 2016).

Other ASCA recommendations of percentage of time and school counselor to student ratio were highlighted. However, the CDE included its own breakdown of services by percentage and grade level. Other items from the third edition of the ASCA National Model were referenced or included as graphics within the model (ASCA, 2012). The purpose of the manual was to provide samples of the evaluation process for both school counselors and administrators. Samples highlighted a demonstration of implementations of a CSCP that was geared toward the needs of the students. A complete chart was included to guide ratings with artifacts submitted to support school administrators in the appropriate evaluation of school counselors. The scoring rubric addresses different levels of practice among various elements with respect to the core functions of what the state has defined as the school counselor's roles (CDE, n.d.). While the rubric lacks core ASCA language, it does address ethical practice, evidence-based programming, and alignment with laws and policies at all levels.

\section{ASCA National Model School Counselor Performance Appraisal Template}

The School Counselor Performance Appraisal within the National Model is intended to be used as a template that can be connected to other frameworks used by the school district or the state department of education (ASCA, 2019a). School counselors are encouraged to have a qualified individual, such as a building administrator, complete the evaluation. The language within this template should be used to create a district or state version of a school counselor evaluation. Ultimately, ASCA states that the evaluation should assess the fundamental elements of a CSCP that includes data-informed goals and services.

We encourage our readers to reference the current edition of the ASCA National Model for a complete list of the core items that can be included in a school counselor's performance evaluation. With ASCA's recommendation to have a statewide performance evaluation, the preceding sections highlighted state-specific examples of evaluations that are designed to measure school counselors' performance within that state. This is not an exhaustive list of all states that have incorporated an evaluation system for school counselors. In the past, school counselors have been evaluated using the same state standard evaluations as teachers. 


\section{Conclusions}

The goal of Chapter 3 is to help you understand how assessment intersects with each of the quadrants of the ASCA National Model. We covered how assessments provide a starting point for school counselors when building or restructuring a CSCP. The assessments covered within this chapter are valid and reliable in helping school counselors make informed decisions regarding their CSCP. While some of the assessments are dated in comparison to the recently updated fourth edition of the ASCA National Model, each assessment discussed is still relevant to current school counseling practices. Importantly, each assessment demonstrates how school counselors can incorporate various assessments into the development, implementation, and management of a CSCP.

\section{Additional Readings}

American School Counselor Association. (2019a). ASCA national model: A framework for school counseling programs (4th ed.). American School Counselor Association.

American School Counselor Association. (2019b). ASCA national model implementation guide: Manage and assess (2nd ed.). American School Counselor Association.

Goodman-Scott, E., Betters-Bubon, J., \& Donohue, P. (Eds.). (2019). The school counselor's guide to multi-tiered systems of support. Routledge.

Hatch, T. (2014). The use of data in school counseling: Hatching results for students, programs, and the profession. Corwin.

Zyromski, B. \& Mariani, M.A. (2016). Facilitating evidence-based, data-driven school counseling: A manual for practice. Corwin.

\section{Tools and Resources}

- A copy of the SCARS can be located through the UMass Amherst School Counselor Resources (https:// www.cscoreumass.org/sc-resources)

- A copy of the Strengths \& Difficulties Questionnaire and related items be accessed through the developer's website (https://www.sdqinfo.org/py/sdqinfo/b0.py)

\section{Key Points}

- The use of assessments can be incorporated into each of the four quadrants of the ASCA National Model.

- Valid and reliable assessments can help school counselors assess the current state of their CSCP.

- School counselors can use valid and reliable assessments to inform both their direct and indirect service delivery.

- Assessments shape the direction of all school counseling services and provide school counselors with data to enhance their service efficacy and advocacy efforts.

\section{Questions for Reflection}

- How can a school counselor use the SCPIS to shape their practice?

- How are assessments utilized in the Manage quadrant of the ASCA National Model?

- Which assessments are connected to direct student services and how can these assessments be used by school counselors who are working directly with students? 


\section{References}

American School Counselor Association. (2012). ASCA national model: A framework for school counseling programs (3rd ed.). American School Counselor Association.

American School Counselor Association. (2014). ASCA mindsets \& behaviors for student success K-12 college-and career-readiness standards for every student. https:/www.schoolcounselor.org/getmedia/7428a787-a452 -4abb-afec-d78ec77870cd/Mindsets-Behaviors.pdf

American School Counselor Association. (2016). ASCA ethical standards for school counselors. https://www .schoolcounselor.org/getmedia/f041cbd0-7004-47a5-ba01-3a5d657c6743/Ethical-Standards.pdf

American School Counselor Association. (2019a). ASCA national model: A framework for school counseling programs (4th ed.). American School Counselor Association.

American School Counselor Association. (2019b). ASCA national model implementation guide: Manage and assess (2nd ed.). American School Counselor Association.

American School Counselor Association. (2019c). ASCA school counselor professional standards and competencies. https://www.schoolcounselor.org/getmedia/a8d59c2c-51de-4ec3-a565-a3235f3b93c3/SC -Competencies.pdf

Clemens, E., Milsom, A., \& Cashwell, C. (2009). Using leader-member exchange theory to examine principalschool counselor relationships, school counselors' roles, job satisfaction, and turnover intentions.Professional School Counseling, 13(2), 75-85. https://doi.org/10.5330/PSC.N.2010-13.75

Clemens, E. V., Carey, J. C., \& Harrington, K. M. (2010). The School Counseling Program Implementation Survey: Initial instrument development and exploratory factor analysis. Professional School Counseling, 14(2), 125-134. https://doi.org/10.1177/2156759X100140020

Colorado Department of Education \& Practitioners Across Colorado. (2016). Colorado state model evaluation system for specialized service professionals: Practical ideas guide for evaluating school counselors. https://www .cde.state.co.us/educatoreffectiveness/practical_ideas_guide_schoolcounselors

Colorado Department of Education. (n.d.). Rubric for evaluating Colorado special services providers: School counselors. https://www.cde.state.co.us/educatoreffectiveness/sspcounselorrubric

Colorado Department of Education. (2015). Colorado state model evaluation system for school counselors: 20132014 pilot report. https://www.cde.state.co.us/educatoreffectiveness/ssppilotreportcounselor

Dahir, C. A., \& Stone, C. B. (2006). Preparing the next generation: Implementing new paradigms for school counseling preservice and practice. In Ideas and Research You Can Use: VISTAS 2006. https://www.counseling .org/docs/default-source/vistas/preparing-the-next-generation-implementing-new-paradigms-for-school -counseling-preservice-and-practce.pdf?sfvrsn=2dd7e2c_10

Dahir, C. A., \& Stone, C. B. (2009). School counselor accountability: The path to social justice and systemic change. Journal of Counseling \& Development, 87(1), 12-20. https://doi.org/10.1002/j.1556-6678.2009 .tb00544.x

Dimmitt, C., Carey, J. C., \& Hatch, T. (2007). Evidence-based school counseling: Making a difference with data-driven practices. Corwin.

DuFour, R., Guidice, A., Magee, D., Martin, P., \& Zivovic, B. (2002). The student support team as a professional learning community. In C. D. Johnson \& S. K. Johnson (Eds.), Building stronger school counseling programs: Bringing futuristic approaches into the present (pp. 19-36). CAPS.

Elsner, D., \& Carey, J. (2005). School counseling program implementation survey. Unpublished assessment instrument.

Erford, B. T. (2019). Culturally competent school counselors: Affirming diversity by challenging oppression. In B. T. Erford (Ed.), Transforming the school counseling profession (5th ed., pp. 172-189). Pearson.

Goodman, A., Lamping, D. L., \& Ploubidis, G. B. (2010). When to use broader internalising and externalising subscales instead of the hypothesized five subscales on the Strengths and Difficulties Questionnaire (SDQ): Data from British parents, teachers and children. Journal of Abnormal Child Psychology, 38(8), 1179-1191. https://doi.org/10.1007/s10802-010-9434-x

Goodman, R. (1997). The Strengths and Difficulties Questionnaire: A research note. Child Psychology \& Psychiatry \& Allied Disciplines, 38(5), 581-586. https://doi.org/10.1111/j.1469-7610.1997.tb01545.x

Goodman, R., Meltzer, H., \& Bailey, V. (1998). The Strengths and Difficulties Questionnaire: A pilot study on the validity of the self-report version. European Child \& Adolescent Psychiatry, 7(3), 125-130. https://doi .org/10.1007/s007870050057

Goodman-Scott, E., Betters-Bubon, J., \& Donohue, P. (Eds.). (2019). The school counselor's guide to multi-tiered systems of support. Routledge. 
Goodman-Scott, E., \& Ockerman, M. S. (2019). Integrating school counseling and MTSS. In E. Goodman-Scott, J. Betters-Bubon, \& P. Donohue (Eds.), The school counselor's guide to multi-tiered systems of support (pp. 29-61). Routledge.

Gysbers, N. C. \& Henderson, P. (2001). Comprehensive guidance and counseling programs: A rich history and bright future. Professional School Counseling, 4(4), 246-256.

Gysbers, N. C., Stanley, J. B., Kosteck-Bunch, L., Magnuson, C. S., \& Starr, M. F. (2017). Missouri comprehensive school counseling program: A manual for program development, implementation, evaluation, and enhancement. http://www.missouricareereducation.org/doc/guidemanual/Manual.pdf

Hatch, T. (2014). The use of data in school counseling: Hatching results for students, programs, and the profession. Corwin.

Johnson, C. D., \& Johnson, S. K. (2002). Building stronger school counseling programs: Bringing futuristic approaches into the present. CAPS.

Mason, E. C. M., Ockerman, M. S., \& Chen-Hayes, S. F. (2013). Change-Agent-for-Equity (CAFE) model: A framework for school counselor identity. Journal of School Counseling, 11(4), 1-25. http://www.jsc.montana .edu/articles/v11n4.pdf

Myrick, R. D. (2011). Developmental guidance and counseling: A practical approach (5th ed.). Educational Media Corporation.

Nelson, M. D., \& Tarabochia, D. S. (2020). A primer on designing a school counseling curriculum. Journal of School Counseling, 18(6), 1-26. http:/www.jsc.montana.edu/articles/v18n6.pdf

Ohio Department of Education. (2015). Ohio standards for school counselors. http://education.ohio.gov/ getattachment/Topics/Career-Tech/Career-Connections/School-Counselors/School-Counselor-Standards -and-Evaluation/SchoolCounselorStandards.pdf.aspx

Ohio Department of Education. (2016a). Evaluation framework for school counselors. http://education.ohio .gov/getattachment/Topics/Career-Tech/Career-Connections/School-Counselors/School-Counselor -Standards-and-Evaluation/School-Counselor-Evaluation-Framework-04-15-2016.pdf.aspx

Ohio Department of Education. (2016b). Ohio school counselor evaluation model. http://education.ohio .gov/getattachment/Topics/Career-Tech/Career-Connections/Resources-for-School-Counselors/School -Counselor-Standards-and-Evaluation/OSCES-Model.pdf.aspx

Ohio Department of Education. (2020). School counselor standards and evaluation. http://education.ohio.gov/ Topics/Teaching/Educator-Evaluation-System/School-Counselor-Standards-and-Evaluation

Scarborough, J. L. (2005a). The School Counselor Activity rating Scale: An instrument for gathering process data. Professional School Counseling, 8(3), 274-283. https://www.jstor.org/stable/42732469

Scarborough, J. L. (2005b). The School Counselor Activity Rating Scale. https://85366e73-a5db-4b8c-a573 -ed2d99e88528.filesusr.com/ugd/b96ded_c73e4fd77d814fc1903f452b3ad314f4.pdf

SCUTA. (2020). What is SCUTA? https://www.myscuta.com/

UMass Amherst College of Education. (2019). School counselor resources: Instruments. https://www .cscoreumass.org/sc-resources

Youth in Mind. (2015a, January, 1). What is the SDQ?. https://www.sdqinfo.org/ao.htm

Youth in Mind. (2015b, December, 9). Downloadable SDQs and related items. https://www.sdqinfo.org/py/ sdqinfo/b0.py

Zyromski, B., \& Mariani, M. A. (2016). Facilitating evidence-based, data-driven school counseling: A manual for practice. Corwin. 
